\title{
Calcium requirements for bone growth in Canadian boys and girls during adolescence
}

\author{
Hassanali Vatanparast ${ }^{1}$, Donald A. Bailey ${ }^{2,3}$, Adam D. G. Baxter-Jones ${ }^{2}$ and Susan J. Whiting ${ }^{1 *}$ \\ ${ }^{1}$ College of Pharmacy and Nutrition, University of Saskatchewan, 110 Science Place, Saskatoon, SK, Canada S7N 5C9 \\ ${ }^{2}$ College of Kinesiology, University of Saskatchewan, Saskatoon, SK, Canada S7N 5B2 \\ ${ }^{3}$ School of Human Movement Studies, University of Queensland, Brisbane, QLD 4072, Australia
}

(Received 3 March 2009 - Revised 21 August 2009 - Accepted 24 August 2009 - First published online 26 October 2009)

Adequate dietary intake during the growth period is critical for bone mineral accretion. In 1997, an adequate intake (AI) of $1300 \mathrm{mg} / \mathrm{d}$ Ca was set for North American adolescents aged 9-18 years based on best available data. We determined bone Ca accrual values from age 9 to 18 years taking into account sex and maturity. Furthermore, we used the accrual data to estimate adolescents' Ca requirements. Total body bone mineral content (TBBMC) of eighty-five boys and sixty-seven girls participating in the Saskatchewan Paediatric Bone Mineral Accrual Study were used to determine annual TBBMC accumulation over the pubertal growth period. Using a similar factorial approach as the AI, we estimated Ca requirements of adolescent boys and girls for two age groups: 9-13 and 14-18 years. Between 9 and 18 years, boys accrued 198.8 (SD 74.5) $\mathrm{g}$ bone mineral content (BMC) per year, equivalent to 175.4 (SD 65.7) $\mathrm{mg}$ Ca per $\mathrm{d}$ with the maximum BMC accrual of $335.9 \mathrm{~g}$ from age 13 to 14 years. Girls had 138.1 (SD 64.2) g BMC per year, equalling121.8 (SD 56.6) $\mathrm{mg}$ Ca per d with the maximum annual BMC accrual of $266.0 \mathrm{~g}$ from age 12 to 13 years. Differences were observed between both sex and age groups with respect to Ca needs: boys and girls aged 9-13 years would require $1000-1100 \mathrm{mg} / \mathrm{d} \mathrm{Ca}$, and from age 14 to 18 years, the mean Ca requirements would be relatively stable at $1000 \mathrm{mg} / \mathrm{d}$ for girls but would rise to $1200 \mathrm{mg} / \mathrm{d}$ for boys.

Calcium requirements: Bone mineral accrual: Adolescence

The development of peak bone mass during the growing years is considered an important determinant for future risk of osteoporosis in later life ${ }^{(1-3)}$. An adequate $\mathrm{Ca}$ intake during the growth period therefore may be critical in maximising bone mineral potential. The importance of $\mathrm{Ca}$ for skeletal growth has led to the setting of a North American Dietary Reference Intake (DRI) adequate intake level of $\mathrm{Ca}$ for adolescents aged 9-18 years, $1300 \mathrm{mg} / \mathrm{d}$ from a range of $1100-1600 \mathrm{mg} / \mathrm{d}$ based on available evidence at that time ${ }^{(4)}$. However, in 1997, the lack of sufficient longitudinal Ca accrual data for boys and girls during the 10 years of adolescence meant the expert panel was unable to estimate $\mathrm{Ca}$ requirements related to either sex differences or the effects of maturation both of which are known to impact $\mathrm{Ca}$ accrual $^{(4)}$.

To derive the adequate intake for $\mathrm{Ca}$, the DRI panel on $\mathrm{Ca}$ used three major approaches. These included (1) Ca balance studies of subjects consuming variable amounts of $\mathrm{Ca}$, (2) clinical trials on adolescents investigating the response of changes in bone mineral content/density to varying Ca intakes, and (3) a factorial model approach ${ }^{(4,5)}$. Non-linear regression equations were used to determine the $\mathrm{Ca}$ intake required to achieve a desirable retention of $\mathrm{Ca}(282 \mathrm{mg} / \mathrm{d}$ for boys and $212 \mathrm{mg} / \mathrm{d}$ for girls) with a plateau balance from balance studies conducted in Caucasian girls aged $11-14$ years ${ }^{(4)}$. Evidence from randomised trials in children and adolescents revealed additional intake of $\mathrm{Ca}$ in habitual intake of about $900 \mathrm{mg} / \mathrm{d}$ positively affects bone mineral accretion, particularly during the pre-pubertal stage. However, the effect is not maintained post intervention $^{(4)}$. In the factorial approach, Ca requirements were estimated based on combining $\mathrm{Ca}$ retention and $\mathrm{Ca}$ loss via various routes (skin, urine and faecal) by apparently healthy individuals, while considering the absorption fraction of $\mathrm{Ca}^{(4)}$. The values for $\mathrm{Ca}$ retention were calculated to be $212 \mathrm{mg} / \mathrm{d}$ for girls and $282 \mathrm{mg} / \mathrm{d}$ for boys. These were based upon a cross-sectional analysis of bone mineral accrual during the 2 years surrounding the age of peak bone mineral content accrual in 115 girls and 113 boys ${ }^{(5)}$. For boys, peak bone mineral content (BMC) accrual occurred at 14.5 years of age; whereas for girls, peak BMC accrual occurred earlier, at 13.0 years of age. It has been suggested that applying these particular 2-year retention values for Ca likely overestimates the requirement throughout the whole adolescent period, i.e. from 9 to 18 years. Using $\mathrm{Ca}$ balance data in adult males (aged 28.2 (SD 7.7) years, $n$ 82) and females (aged 47.0 (SD 18.5) years, $n$ 73), lower Ca requirement of $741 \mathrm{mg} / \mathrm{d}$ (where $\mathrm{Ca}$ balance is neutral) has been estimated for adult males and females compared to previous estimates ${ }^{(6)}$. No estimate of $\mathrm{Ca}$ requirement for adolescents (9-18 years) has been reported recently. We now present longitudinal data covering the same age span, 9-18 years of age and report the average accumulation of $\mathrm{Ca}$ during these years in Caucasian Canadian boys and girls ${ }^{(4)}$. 


\section{Methods}

Study participants and design

The data are taken from subjects participating in the University of Saskatchewan's Paediatric Bone Mineral Accrual Study ${ }^{(5,7-9)}$. The study used a mixed longitudinal design incorporating cohorts at 8 years of age. The study was initiated in 1991, when 228 boys (113) and girls (115) aged 8-15 years were recruited (220 were dual-energy X-ray absorptiometry scanned). From 1992 to 1993 an additional 31-, 8- and 9 -year-old subjects were recruited. The age range of the sample was 12-21 after 6 years of follow up (1997). Bone mineral was measured annually until 1997 at which time 197 individuals had been repeatedly measured on more than one occasion. As the relative size of the overlapping cohorts remained the same, it was possible to estimate a 14-year developmental pattern (8-20 years) from 7 years of data collection. For the present analysis, we used data in DRI age range for adolescence (9-18 years). Subjects were included who had a measure of biological age at peak height velocity (PHV) and continuous measures of BMC accrual for at least two or more consecutive time points; 152 participants (eighty-five boys and sixty-seven girls) were eligible. Eligible children were Caucasian and had no history of chronic disease or chronic medication use; no medical conditions, allergies or medications known to influence bone metabolism or $\mathrm{Ca}$ balance. They were recruited from two elementary schools in middle-class neighbourhoods in Saskatoon, Saskatchewan Canada. The present study was conducted according to the guidelines laid down in the Declaration of Helsinki and all procedures involving human subjects/patients were approved by the University of Saskatchewan Advisory Committee on Ethics in Human Experimentation. Written informed consent was obtained from all the subjects as well as parent/guardians.

Age

A decimal value for chronological age was determined by subtracting the date of birth from the date of measurement ${ }^{(10)}$. Chronological age groups were formed by using 1 -year intervals where, for example, the 9.49-10.49-year-old participants would be considered 10 years of age.

\section{Dietary calcium intake}

Food intake was assessed via serial 24-h recalls conducted both at the participating schools and in the hospital at the time of the bone scans. The target number of recalls was three recalls/year collected in different seasons. Approximately, $10 \%$ of recalls were discarded for being implausible (below $4.18 \mathrm{MJ}$ or above $20.92 \mathrm{MJ}$ ). All days of the week, except Friday and Saturday were included. To obtain $\mathrm{Ca}$ intake, food intake from the 24-h recalls was analysed using a nutritional assessment software package (NUTS Nutritional Assessment System, version 3.7 Quilchena Consulting Ltd, Victoria, BC, Canada). Ca supplement use was included in $\mathrm{Ca}$ intake data when supplement use was considered consistent. To obtain usual intake, intake of $\mathrm{Ca}$ from serial 24-h recalls was averaged for each year of study (Table 1$)^{(8)}$.

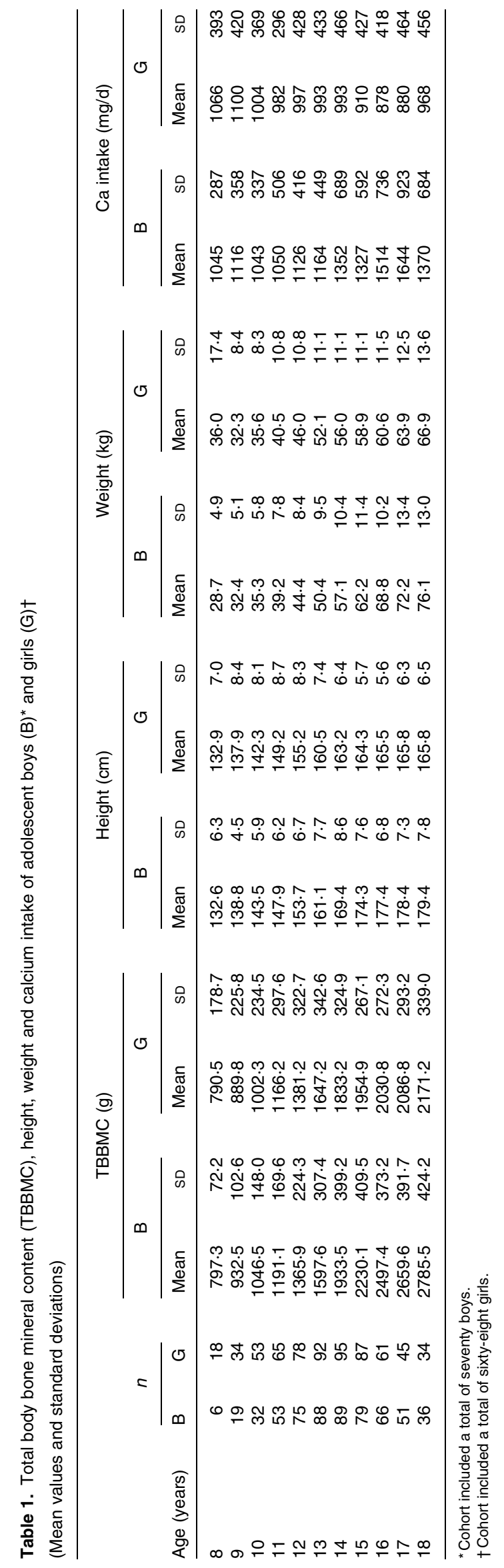




\section{Bone measurements}

Bone measurements were obtained by annual dual-energy X-ray absorptiometry scans of the whole body. They were carried out by one of two experienced operators using a Hologic QDR 2000 (Hologic, Waltham, MA, USA) in the array mode using enhanced global software version 7.10. To minimise operator-related variability, the same qualified person analysed all whole body scans, using enhanced software version $5.67 \mathrm{~A}$. In our laboratory, in vivo short-term reproducibility for total body $\mathrm{BMC}$ is $0.60 \%$. A Victoreen Ion Chamber Survey Meter (Model 450p) measured entrance radiation dose. When this surface dose was corrected for body attenuation, subject age and type and volume of tissue being irradiated, the effective dose equivalent was less than $1 \mathrm{mrem}$. Measurements are presented for Total body bone mineral content (TBBMC), unadjusted for body size, at defined age points. Annual $\mathrm{Ca}$ retention (g/year) and daily $\mathrm{Ca}$ retention $(\mathrm{mg} / \mathrm{d})$ were derived by assuming that $32.2 \%$ $\mathrm{Ca}$ in bone mineral content ${ }^{(11)}$.

\section{Anthropometric measurements}

Anthropometric measurements were taken at 6-month intervals by trained personnel following a standard protocol ${ }^{(7)}$. Standing heights were recorded without shoes as stretch stature to $0 \cdot 1 \mathrm{~cm}$ using a wall mounted stadiometer. Body mass was measured to $0.01 \mathrm{~kg}$ on a calibrated electronic scale.

\section{Analysis}

By plotting TBBMC values over time (age in years), distance and velocity curves were generated (GraphPad PRISM 4, GraphPad Software Inc., La Jolla, CA, USA; www.graphpad.com) in order to find TBBMC at each discrete age. Data are presented as means and standard deviations. Sex differences in TBBMC values at each age were tested using Student's $t$ test. $\alpha$ was set to a value of $0 \cdot 05$.
We used the same factorial approach for $\mathrm{Ca}$ requirements of adolescents as DRI report on $\mathrm{Ca}(\mathrm{Ca}$ requirements $=$ $(\mathrm{Ca}$ needs $+\mathrm{Ca}$ losses $) / 38 \%)^{(4)}$. In this method, we added $\mathrm{Ca}$ needs for growth to $\mathrm{Ca}$ losses via urine, faeces and sweat and adjusting the results for absorption (38\%). $\mathrm{Ca}$ needs (Ca accretion) were obtained from our longitudinal data for boys and girls in age groups 9-13 and 14-18 years. We used the same values for Ca loss that DRI panel used (Faecal Ca, 112 and $108 \mathrm{mg} / \mathrm{d}$ in girls and boys respectively; sweat loss, $55 \mathrm{mg} / \mathrm{d}$ in boys $)^{(4)}$. However, when recent data were available for Ca loss, we used them ${ }^{(12,13)}$. For girls, we used $\mathrm{Ca}$ sweat loss values from data reported by Palacios et al. ${ }^{(12)}(51 \mathrm{mg} / \mathrm{d})$. For urinary excretion, recent values taken from Braun et al. ${ }^{(13)}$ (106 and $85 \mathrm{mg} / \mathrm{d}$ in girls and boys respectively). These data were provided by the authors of that study.

\section{Results}

Not every subject completed all 7 years of data collection. However, data were overlapping and it can be seen that TBBMC of the subjects from age 8 through to age 18 years increased by 3.5 times in boys and 2.7 times in girls (Table 1). In our cohort at ages 8 and 9 years, boys and girls began adolescence with similar TBBMC, yet by 14 years of age boys had more TBBMC, were taller and had higher $\mathrm{Ca}$ intake than girls $(P<0 \cdot 01)$. As shown in Table 2, boys accrued more TBBMC during their peak years (ages 14-16 years) than girls during their peak years (ages 12-14 years); in boys, net accrual through adolescence was $31 \%$ greater than in girls. However, Ca retention per height $(\mathrm{mg} / \mathrm{d}$ per $\mathrm{cm})$ varied over adolescence (Fig. 1). The peak $\mathrm{Ca}$ accrual per unit height was achieved at the age of PHV velocity in both sexes.

Using the same factorial approach as DRI report on $\mathrm{Ca}$, we estimated $\mathrm{Ca}$ retention for the whole adolescence age range of 9-18 years as well as for two subgroups, younger adolescents aged 9-13 years and older adolescents aged 14-18 years, for boys and girls separately. For $\mathrm{Ca}$ retention we used values

Table 2. Bone mineral content retention ( $/$ /year) calculated from total body bone mineral content (TBBMC), calcium retention ( $\mathrm{g} / \mathrm{year})^{\star}, \mathrm{calcium}$ retention $(\mathrm{mg} / \mathrm{d}) \dagger$ of adolescent boys and girls of age $9-18$ years

\begin{tabular}{|c|c|c|c|c|c|c|c|c|c|c|}
\hline \multirow[b]{2}{*}{$\begin{array}{l}\text { Age } \\
\text { (years) }\end{array}$} & \multicolumn{5}{|c|}{ Boys } & \multicolumn{5}{|c|}{ Girls } \\
\hline & $n$ & $\begin{array}{l}\text { TBBMC } \\
\text { (g) }\end{array}$ & $\begin{array}{l}\text { Net accrual } \\
\quad(\mathrm{g})\end{array}$ & $\begin{array}{l}\text { Ca retention/year } \\
\text { (g) }\end{array}$ & $\begin{array}{l}\text { Ca retention/d } \\
(\mathrm{mg})\end{array}$ & $n$ & $\begin{array}{l}\text { TBBMC } \\
\text { (g) }\end{array}$ & $\begin{array}{l}\text { Net accrual } \\
\quad(\mathrm{g})\end{array}$ & $\begin{array}{l}\text { Ca retention/year } \\
\text { (g) }\end{array}$ & $\begin{array}{l}\text { Ca retention/d } \\
(\mathrm{mg})\end{array}$ \\
\hline 8 & 6 & $797 \cdot 3$ & - & - & - & 18 & 790.5 & - & - & - \\
\hline 9 & 19 & 932.5 & $135 \cdot 2$ & 43.5 & $119 \cdot 3$ & 34 & 889.8 & 99.4 & 32.0 & $87 \cdot 7$ \\
\hline 10 & 32 & $1046 \cdot 5$ & 114.0 & $36 \cdot 7$ & $100 \cdot 6$ & 53 & $1002 \cdot 3$ & 112.5 & $36 \cdot 2$ & $99 \cdot 3$ \\
\hline 11 & 53 & 1191.1 & 144.5 & 46.5 & 127.5 & 65 & $1166 \cdot 2$ & $163 \cdot 8$ & $52 \cdot 8$ & 144.5 \\
\hline 12 & 75 & $1365 \cdot 9$ & 174.8 & $56 \cdot 3$ & $154 \cdot 2$ & 78 & $1381 \cdot 2$ & $215 \cdot 1$ & $69 \cdot 2$ & $189 \cdot 7$ \\
\hline 13 & 88 & 1597.6 & 231.7 & 74.6 & 204.4 & 92 & $1647 \cdot 2$ & 266.0 & 85.7 & $234 \cdot 7$ \\
\hline 14 & 89 & 1933.5 & 335.9 & $108 \cdot 2$ & $296 \cdot 3$ & 95 & $1833 \cdot 2$ & $186 \cdot 0$ & 59.9 & $164 \cdot 1$ \\
\hline 15 & 79 & $2230 \cdot 1$ & $296 \cdot 6$ & 95.5 & $261 \cdot 7$ & 86 & 1954.9 & $121 \cdot 6$ & 39.2 & $107 \cdot 3$ \\
\hline 16 & 66 & 2497.4 & $267 \cdot 3$ & $86 \cdot 1$ & $235 \cdot 8$ & 61 & $2030 \cdot 8$ & $75 \cdot 9$ & 24.4 & $67 \cdot 0$ \\
\hline 17 & 51 & $2659 \cdot 6$ & $162 \cdot 2$ & $52 \cdot 2$ & $143 \cdot 1$ & 45 & $2086 \cdot 8$ & $56 \cdot 1$ & $18 \cdot 1$ & 49.5 \\
\hline 18 & 36 & 2785.5 & 125.9 & 40.5 & 111.1 & 34 & 2171.2 & $84 \cdot 3$ & $27 \cdot 2$ & 74.4 \\
\hline Mean & - & $1730 \cdot 6$ & $198 \cdot 8$ & 64.0 & $175 \cdot 4$ & - & $1541 \cdot 3$ & $138 \cdot 1$ & 44.5 & $121 \cdot 8$ \\
\hline SD & - & $726 \cdot 1$ & $78 \cdot 6$ & $25 \cdot 3$ & 69.3 & - & 514.4 & $67 \cdot 6$ & 21.8 & $59 \cdot 7$ \\
\hline
\end{tabular}

${ }^{*}$ Calcium retention ( $\mathrm{g} / \mathrm{year}$ ) obtained and daily calcium retention $(\mathrm{mg} / \mathrm{d})$ was derived by assuming $32.2 \%$ calcium in bone mineral content.

$\dagger$ Calcium retention $(\mathrm{mg} / \mathrm{d}$ ) obtained by converting calcium retention values from $\mathrm{g} / \mathrm{year}$ to $\mathrm{mg} / \mathrm{d}$. 


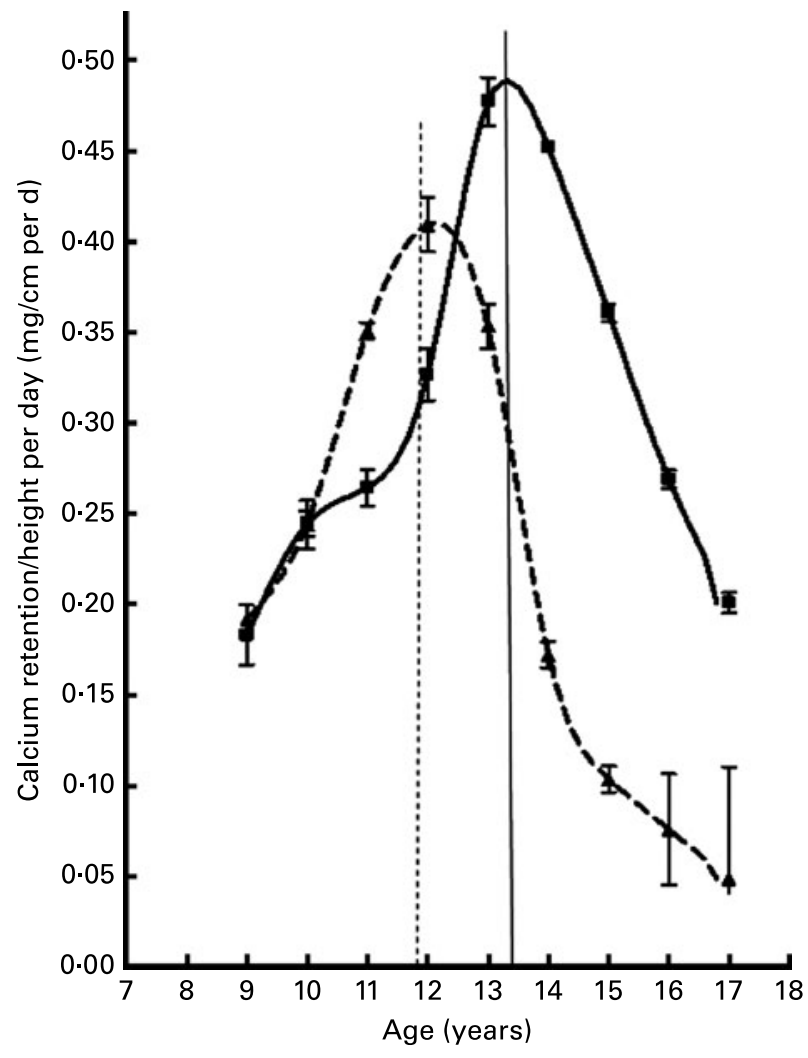

Fig. 1. Calcium retention $(\mathrm{mg} / \mathrm{d})$ per centimetre height in boys and girls during adolescence. Peak height velocity was achieved at age 11.8 years in girls and 13.5 years in boys. $\mathbf{\square}$, Male; $\boldsymbol{\Lambda}$, female.

from Table 2. The resulting calculations, summarised in Table 3, show differences from those values calculated in $1997^{(4)}$. For adolescents aged 9-13 years, the difference in the estimation of $\mathrm{Ca}$ requirements for boys and girls is $81 \mathrm{mg}$ (1024 and $1105 \mathrm{mg}$ in boys and girls, respectively). For adolescents aged $14-18$ years, there is a marked difference in the estimation of $\mathrm{Ca}$ requirements for boys and girls; the value for older girls decreases below $1000 \mathrm{mg}$, while that for older boys increases to $1205 \mathrm{mg}$. None of these estimates approaches the values calculated in the 1997 DRI report on $\mathrm{Ca}$, of $1300 \mathrm{mg}$ for girls and $1500 \mathrm{mg}$ for boys ${ }^{(4)}$.

\section{Discussion}

Using $\mathrm{Ca}$ accrual throughout the complete age span (9-18 years) of the DRI life stage category of 'adolescence, ${ }^{\text {(4) }}$ in the calculation of mean $\mathrm{Ca}$ requirements for boys and girls gave estimates of $1113 \mathrm{mg}$ (approximately $1100 \mathrm{mg}$ ) and $1026 \mathrm{mg}$ (approximately $1000 \mathrm{mg}$ ) respectively. These are lower than those previously reported ${ }^{(5)}$ of $392 \mathrm{mg}$ for boys and $250 \mathrm{mg}$ for girls in which only cross-sectional data from 2 years about the age of PHV were used ${ }^{(5)}$. The DRI panel for $\mathrm{Ca}$ used desirable $\mathrm{Ca}$ retention rather than optimal in its factorial approach. Using the subgroups of adolescence (9-13 and 14-18 years), mean Ca requirements for younger girls and boys adolescents would be similar (1000-1100 mg) but then diverged in the older age group, to less than $1000 \mathrm{mg}$ for girls and more than $1200 \mathrm{mg}$ for boys.

Although before puberty no substantial sex difference has been reported in bone mass of the axial or appendicular skeleton, a sex difference in bone mass becomes expressed during puberty ${ }^{(14,15)}$. In addition to hormonal variation, this difference appears to be the result of a more prolonged bone maturation period in boys than in girls ${ }^{(14,15)}$. In adolescent girls, puberty starts earlier than boys; the gain in bone mass declines rapidly after menarche, and no considerable gains are observed even 2 years later in some bone sites ${ }^{(14)}$. In adolescent boys, bone mineral accrual accelerates, particularly from 13 to 17 years $^{(14)}$. In our cohort, the age of PHV, as an indicator of maturity, occurred at ages 11.8 and 13.4 years in girls and boys, respectively ${ }^{(5)}$. Girls achieved their peak bone mineral content velocity some 8 months later at age of 12.54 years and boys achieved 9 months later at age of 14.05 years $^{(5)}$. Our data suggest that $\mathrm{Ca}$ requirement estimations should be based on age subgroups (9-13 and 14-18 years), as shown in Table 3, and this is more compatible with biological needs of $\mathrm{Ca}$ according to sex difference in timing and pattern of bone and body growth in boys and girls (Table 2).

Our calculation of $\mathrm{Ca}$ requirements using the factorial method described in the DRI report ${ }^{(4)}$, assumes that every other component is valid for the entire adolescence age range. Only limited evidence from well-designed balance studies were available to the DRI panel in 1997. Urinary Ca loss for girls in the original factorial calculation $(106 \mathrm{mg})$

Table 3. Comparison of factorial calculations for determining calcium requirements during adolescence (age 9-18 years) and calcium requirements during peak calcium accretion in white adolescents

\begin{tabular}{|c|c|c|c|c|c|c|c|c|}
\hline \multirow[b]{2}{*}{ Factorial criteria* } & \multicolumn{4}{|c|}{ Females } & \multicolumn{4}{|c|}{ Males } \\
\hline & $\begin{array}{l}\text { During peak } \\
\text { Ca accretion† } \\
(\mathrm{mg} / \mathrm{d})\end{array}$ & $\begin{array}{c}\text { 9-18 years } \\
(\mathrm{mg} / \mathrm{d})\end{array}$ & $\begin{array}{c}9-13 \text { years } \\
(\mathrm{mg} / \mathrm{d})\end{array}$ & $\begin{array}{c}\text { 14-18 years } \\
(\mathrm{mg} / \mathrm{d})\end{array}$ & $\begin{array}{l}\text { During peak } \\
\text { Ca accretion } \dagger \\
(\mathrm{mg} / \mathrm{d})\end{array}$ & $\begin{array}{c}9-18 \text { years } \\
(\mathrm{mg} / \mathrm{d})\end{array}$ & $\begin{array}{c}9-13 \text { years } \\
(\mathrm{mg} / \mathrm{d})\end{array}$ & $\begin{array}{c}14-18 \text { years } \\
(\mathrm{mg} / \mathrm{d})\end{array}$ \\
\hline Ca accretion & $212 \ddagger$ & 121 & 151 & 92 & $282 \S$ & 175 & 141 & 210 \\
\hline Urinary losses & 106 & 106 & 106 & 106 & 127 & 127 & 127 & 127 \\
\hline Endogenous faecal $\mathrm{Ca}$ & 112 & 112 & 112 & 112 & 108 & 108 & 108 & 108 \\
\hline Sweat losses & 55 & 55 & 55 & 55 & 55 & 55 & 55 & 55 \\
\hline Total & 485 & 394 & 424 & 365 & 572 & 465 & 431 & 500 \\
\hline Absorption (\%) & 38 & 38 & 38 & 38 & 38 & 38 & 38 & 38 \\
\hline Adjusted for absorption & 1276 & 1037 & 1116 & 961 & 1505 & 1224 & 1134 & 1316 \\
\hline
\end{tabular}

${ }^{*}$ Criteria listed in Tables 3-4 of Institute of Medicine ${ }^{(4)}$.

†Values taken from Tables 3-4 of Institute of Medicine ${ }^{(4)}$.

$\ddagger$ Age 13 (SD 1.0) years (Hund \& Johnson ${ }^{(6)}$ ).

§Age 14.5 (SD 1.0) years (Hund \& Johnson ${ }^{(6)}$ ) 
was derived from two studies: white girls $11-14$ years $^{(14)}$ and $12 \cdot 5-14.5$ years $^{(4,16)}$. A study by Tylavsky et al. ${ }^{(17)}$ provides an estimate of urinary $\mathrm{Ca}$ excretion for girls at the lower end of the adolescent range (10 years of age) of $68-99 \mathrm{mg}$, the lower value seen when fruit and vegetable consumption was greater than three servings per day ${ }^{(17)}$. However, at the higher end of the adolescent range (17-18 years of age), urinary $\mathrm{Ca}$ excretion would be expected to be higher than the midpoint of adolescence, as adult girls have a higher excretion than peri-pubertal girls ${ }^{(16)}$. A recent $\mathrm{Ca}$ balance study conducted by Braun et al. ${ }^{(13)}$ reported lower urinary Ca excretion with similar $\mathrm{Ca}$ intake in boys than in girls who were matched for sexual maturity. Endogenous faecal losses of girls used in the factorial calculation were based on subjects consuming a $\mathrm{Ca}$ diet of $1330 \mathrm{mg}^{(18)}$ and was similar to that estimated for several adolescent boys on $500-700 \mathrm{mg} \mathrm{Ca} \operatorname{diets}^{(19)}$. Sweat losses of $55 \mathrm{mg}$ in boys were extrapolated ${ }^{(20)}$ from adult values of $60 \mathrm{mg} / \mathrm{d}^{(21)}$. In girls, we used the sweat loss values of $51 \mathrm{mg}$ reported by Palacios et al. ${ }^{(12)}$ in white girls. We used newly available values on $\mathrm{Ca}$ losses either due to the superior sample characteristics or better analytical approaches. Finally, in the factorial calculation, a value of $38 \%$ was used as the estimate of $\mathrm{Ca}$ absorption efficiency. This value was determined from a controlled metabolic study of 11-14 year- old girls given $1330 \mathrm{mg} \mathrm{Ca}$ per $\mathrm{d}^{(18)}$. In the absence of recent reliable data on $\mathrm{Ca}$ absorption efficiency during growth, we used the original value used in DRI factorial method. The value may be an overestimate as it was derived during the time of peak bone mineral accrual for girls, hence $\mathrm{Ca}$ need was greatest. On the other hand, it may underestimate $\mathrm{Ca}$ absorption efficiency at a lower (i.e. $<1330 \mathrm{mg}$ ) $\mathrm{Ca}$ intake and in boys ${ }^{(22,12)}$. Ca absorption efficacy is affected by vitamin $\mathrm{D}$ status. We did not measure vitamin $\mathrm{D}$ status of our subjects; however, sub-optimal vitamin D status has been reported in Canadian children and adolescents ${ }^{(23,24)}$. While all of these values are subjected to further refinement due to age and body size as well as adjustment for $\mathrm{Ca}$ intake, the value for $\mathrm{Ca}$ accrual is the largest component of the factorial equation. We determined $\mathrm{Ca}$ accrual differently in this analysis than we reported previously as the purpose then was to determine the age at, and the value for, peak bone mineral accrual $^{(5,9)}$. We initially found $\mathrm{Ca}$ retention using a crosssectional approach, and these data were used in the DRI factorial calculation for adolescent $\mathrm{Ca}$ requirement ${ }^{(4)}$. We then determined peak $\mathrm{Ca}$ accrual using a longitudinal analysis ${ }^{(9)}$ by finding each subject's peak bone mineral content velocity. The latter analysis found a retention that was approximately $30 \%$ higher than the cross-sectional approach. In the current analysis, we found $\mathrm{Ca}$ retention using longitudinal data and made our calculations based on chronological rather than biological age. Because the DRI life stage of adolescence begins before the onset of puberty and ends after puberty, then calculations using biological age are not necessary.

The Ca accrual values in Table 2 are based on a sample of Caucasian subjects. Therefore, it is not surprising our data are similar but not identical to those in Danish children $^{(25)}$. Using their cross-sectional data of BMC accrual over ages $8.5-18.5$ years (boys, $171 \mathrm{~g} /$ year; girls, $152 \mathrm{~g} /$ year) and calculating $\mathrm{Ca}$ requirements from $\mathrm{Ca}$ accrual (boys, $151 \mathrm{mg} / \mathrm{d}$; girls, $134 \mathrm{mg} /$ year), the resulting $\mathrm{Ca}$ requirements are approximately $1100 \mathrm{mg}$ for both boys and girls (after rounding). One difference in these datasets may be $\mathrm{Ca}$ intake. Our cohort, particularly in the younger age range, has a reasonably good $\mathrm{Ca}$ intake (Table 1); however, as subjects age through adolescence, boys increase $\mathrm{Ca}$ intake while girls show a reduction (Table 1). Some of the decline in $\mathrm{Ca}$ intake may be due to under-reporting that appears to be greater in older adolescent girls than younger girls or boys, based on comparison of energy intake to estimated energy need ${ }^{(26)}$. Ca intake of participants in our cohort seemed to be comparable with values reported by Kalkwarf et al. ${ }^{(27)}$ in a longitudinal study of 1554 healthy children (761 boys, 793 girls) aged 6-16 years of all ethnicities except for boys aged 13-16 years (Table 1). They reported $\mathrm{Ca}$ intake of 1098 (SD 603) $\mathrm{mg} / \mathrm{d}$ ) and 1119 (SD 712) $\mathrm{mg} / \mathrm{d}$ ) for non-black boys at age groups of 9-12 and 13-16 years, respectively. The correspondent values for girls at age groups 9-12 and 13-16 years were $885(\mathrm{SD} \mathrm{527)} \mathrm{mg} / \mathrm{d})$ and $875(\mathrm{SD} \mathrm{556)} \mathrm{mg} / \mathrm{d})^{(27)}$. Difference in dietary assessment method (FFQ in their study) might be responsible for partial dissimilarity. The ages of PHV of girls and boys in our cohort were similar to the Tanner stage 3 (breast) in 12.0 (SD 1.4) years of girls and Tanner stage 4 (testis) in 13.8 (SD 1.2) years in the study by Kalkwarf et al. ${ }^{(27)}$. Consequently, TBBMC of boys and girls in our cohort were located between 50 and 90 TBBMC percentile of non-black boys and girls in corresponding chronological ages in Kalkwarf et al.'s(27) reference values. This may reflect the generalisability of our values to non-black adolescents.

Braun et al. ${ }^{(13)}$ in a 3-week metabolic balance studies of thirty-one boys aged 12-15 years suggested that more $\mathrm{Ca}$ retention in boys than in girls does not necessarily mean that $\mathrm{Ca}$ requirements for boys and girls should be different. They justify that a higher $\mathrm{Ca}$ absorption efficacy and lower $\mathrm{Ca}$ excretion in boys explain why there is no need for sex specific recommendation ${ }^{(13)}$. The explanation of Braun's et $a l$. is based on the balanced studies that they have conducted in boys and girls who were in Tanner pubertal stages (3.5 and 3.7 in boys and girls, respectively). Biological difference exists in boys and girls in bone mineral accrual during growth with boys having more time to lay down mineral mass in their bones (14-17 years), while a sharp decline exists in girls' bone mass accumulation after starting the menstruation period ${ }^{(14,15)}$. By splitting the whole age range of 9-18 years to two age groups: $9-13$ and 14-18 years, we have age and sex-specific values for $\mathrm{Ca}$ retention for adolescent that takes to account the biological difference in time and tempo of maturation in boys and girls.

In summary, we provide new data on $\mathrm{Ca}$ accrual during the whole age range of adolescence (9-18 years), which demonstrates the sex difference in time and pattern of $\mathrm{Ca}$ retention during adolescence. We are, however, unable to provide estimates of variability of $\mathrm{Ca}$ retention. One of the unique aspects of our data is estimating mean $\mathrm{Ca}$ requirements for adolescents using a factorial approach, where $\mathrm{Ca}$ retention data are obtained from longitudinal measurements in participants of different ages all in the same timeframe. In contrast to the 1997 DRI report on $\mathrm{Ca}$, which used $\mathrm{Ca}$ accrual during peak $\mathrm{Ca}$ accretion over only the pubertal growth spurt, we use $\mathrm{Ca}$ retention data from age 9 to 18 years. In the former situation, an adequate intake of $1300 \mathrm{mg}$ was chosen for the whole range of adolescence in both sexes. In the latter, we put forth an 
estimated mean requirement of $1100 \mathrm{mg}$ for boys and girls from age 9 to 13 years. For the age range of 14-18 years we estimated daily $\mathrm{Ca}$ intake of $1200 \mathrm{mg}$ for boys and $1000 \mathrm{mg}$ for girls. The biological differences due to sex in time and tempo of growth spurt have been considered in our calculations of $\mathrm{Ca}$ requirements.

\section{Acknowledgements}

Author contributions were as follows: H. V. performed the statistical data analyses and was involved in writing the manuscript. S. J. W was involved in writing the critical revision of the manuscript for important intellectual content and interpretation of results. S. J. W., D. A. B. and A. D. G. B.-J. were involved in developing the Paediatric Bone Mineral Accrual Study protocol and conducting the study. All the authors actively contributed to the revision of the manuscript. We thank all of the participants and their parents who generously donated their time to the University of Saskatchewan Paediatric Bone Mineral Accrual Study. There were no potential conflicts of interests for the authors of this manuscript. The Paediatric Bone Mineral Accrual Study has been supported in part by grants from, the Canadian National Health and Research Development, the Canadian Institute of Health Research and the Saskatchewan Health Research Foundation.

\section{References}

1. Bailey DA (1999) Prevention of osteoporosis: a pediatric concern. In Lifestyle Medicine, pp. 578-584 [JM Rippe, editor]. Malden, MA: Blackwell Science.

2. Matkovic V, Jelic T, Wardlaw G, et al. (1994) Timing of peak bone mass in Caucasian females and its implication for the prevention of osteoporosis. J Clin Invest 93, 799-808.

3. Heaney RP, Abrams S, Dawson-Hughes B, et al. (2000) Peak bone mass. Osteoporos Int 11, 985-1009.

4. Institute of Medicine (1997) Dietary Reference Intakes: Calcium, Magnesium, Phosphorus, Vitamin D, and Fluoride, pp. 71-145. Washington, DC: National Academy Press.

5. Martin AD, Bailey DA, McKay HA, et al. (1997) Bone mineral and calcium accretion during puberty. Am J Clin Nutr 66, 611-615.

6. Hunt CD \& Johnson LK (2007) Calcium requirements: new estimations for men and women by cross-sectional statistical analyses of calcium balance data from metabolic studies. $\mathrm{Am}$ J Clin Nutr 86, 1054-1063.

7. Bailey DA (1997) The Saskatchewan pediatric bone mineral accrual study: Bone mineral acquisition during the growing years. Int J Sports Med 18, S191-S194.

8. Iuliano-Burns S, Whiting SJ, Faulkner RA, et al. (1999) Levels, sources, and seasonality of dietary calcium intake in children and adolescents enrolled in the University of Saskatchewan Pediatric Bone Mineral Accrual Study. Nutr Res 19, 1471-1483.

9. Bailey D, Martin A, McKay H, et al. (2000) Calcium accretion in girls and boys during puberty: a longitudinal analysis. $J$ Bone Miner Res 15, 2245-2250.
10. Baxter-Jones ADG, Mirwald RL, McKay H, et al. (2003) A longitudinal analysis of sex differences in bone mineral accrual in healthy 8-19 year old boys and girls. Ann Hum Biol 30, 160-175.

11. Ellis KJ, Shypailo RJ, Hergenroeder A, et al. (1996) Total body calcium and bone mineral content: comparison of dual-energy $\mathrm{X}$-ray absorptiometry with neutron activation analysis. $J$ Bone Miner Res 11, 843-848.

12. Palacios C, Wigertz K, Martin B, et al. (2003) Sweat mineral loss from whole body, patch and arm bag in white and black girls. Nutr Res 23, 401-411.

13. Braun M, Martin BR, Kern M, et al. (2006) Calcium retention in adolescent boys on a range of controlled calcium intakes. Am J Clin Nutr 84, 414-418.

14. Bonjour JP, Ammann P, Chevalley T, et al. (2003) Nutrition aspects of bone growth: an overview. In Nutritional Aspects of Bone Health, pp. 111-127 [S New and JP Bonjour, editors]. Cambridge: The Royal Society of Chemistry.

15. Malina RM, Bouchard C \& Bar-Or O (2004) Growth, Maturation, and Physical Activity. Champaign, IL: Human Kinetics.

16. Weaver CM, Martin BR, Plawecki KL, et al. (1995) Differences in calcium metabolism between adolescent and adult females. Am J Clin Nutr 61, 577-581.

17. Tylavsky FA, Holliday K, Danish R, et al. (2004) Fruit and vegetable intake is an independent predictor of bone size in early-pubertal children. Am J Clin Nutr 79, 311-317.

18. Wastney ME, Ng J, Smith D, et al. (1996) Differences in calcium kinetics between adolescent girls and young women. Am J Physiol 271, R208-R216.

19. Abrams SA, Estaban NV, Viera NE, et al. (1992) Developmental changes in calcium kinetics in children assessed using stable isotopes. J Bone Miner Res 7, 287-293.

20. Peacock M (1991) Calcium absorption efficiency and calcium requirements in children and adolescents. Am J Clin Nutr 54, 261S-265S.

21. Charles P, Jensen FT, Mosekilde L, et al. (1983) Calcium metabolism evaluated by ${ }^{47} \mathrm{Ca}$ kinetics: estimation of dermal calcium loss. Clin Sci 65, 415-422.

22. Heaney RP, Weaver CM \& Fitzsimmons ML (1990) Influence of calcium load on absorption fraction. J Bone Miner Res $\mathbf{5}$, $1135-1138$.

23. Vieth R, Cole DE, Hawker GA, et al. (2001) Wintertime vitamin $\mathrm{D}$ insufficiency is common in young Canadian women, and their vitamin D intake does not prevent it. Eur $J$ Clin Nutr 55, 1091-1097.

24. Roth DE, Martz P, Yeo R, et al. (2005) Are national vitamin D guidelines sufficient to maintain adequate blood levels in children? Can J Public Health 96, 443-449.

25. Molgaard C, Thomsen BL \& Michaelsen KF (1999) Whole body bone mineral accretion in healthy children and adolescents. Arch Dis Child 81, 10-15.

26. Carter LM, Whiting SJ, Drinkwater DT, et al. (2001) Self-reported calcium intake and bone mineral content in adolescents. J Am Coll Nutr 20, 502-509.

27. Kalkwarf HJ, Zemel BS, Gilsanz V, et al. (2007) The bone mineral density in childhood study: bone mineral content and density according to age, sex and race. J Clin Endocrinol Metab 92, 2087-2099. 